\title{
NBL, Rat Strain
}

National Cancer Institute

\section{Source}

National Cancer Institute. NBL, Rat Strain. NCI Thesaurus. Code C14410.

Good reproductive performance. Hyperplasia and dysplasia of the dorsolateral prostate caused by implantation of testosterone and estradiol-17-filled silastic capsules.

Prolonged implantation leads to prostatic carcinoma (Leav et al 1988, 1989). 